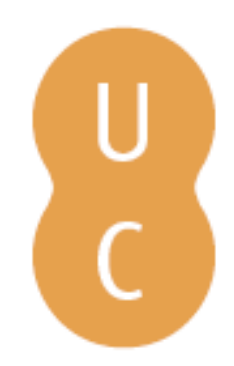

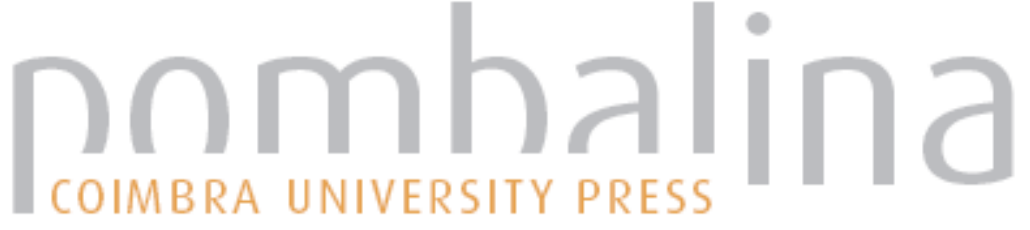

\section{Mais de um século em prol da agricultura: a Gazeta das Aldeias}

Autor(es): $\quad$ Coelho, Maria Helena da Cruz

Publicado por: Imprensa da Universidade de Coimbra

URL persistente:

URI:http://hdl.handle.net/10316.2/43687

DOI:

DOI:https://doi.org/10.14195/978-989-26-1364-2_2

Accessed : $\quad$ 26-Apr-2023 11:58:45

A navegação consulta e descarregamento dos títulos inseridos nas Bibliotecas Digitais UC Digitalis, UC Pombalina e UC Impactum, pressupõem a aceitação plena e sem reservas dos Termos e Condições de Uso destas Bibliotecas Digitais, disponíveis em https://digitalis.uc.pt/pt-pt/termos.

Conforme exposto nos referidos Termos e Condições de Uso, o descarregamento de títulos de acesso restrito requer uma licença válida de autorização devendo o utilizador aceder ao(s) documento(s) a partir de um endereço de IP da instituição detentora da supramencionada licença.

Ao utilizador é apenas permitido o descarregamento para uso pessoal, pelo que o emprego do(s) título(s) descarregado(s) para outro fim, designadamente comercial, carece de autorização do respetivo autor ou editor da obra.

Na medida em que todas as obras da UC Digitalis se encontram protegidas pelo Código do Direito de Autor e Direitos Conexos e demais legislação aplicável, toda a cópia, parcial ou total, deste documento, nos casos em que é legalmente admitida, deverá conter ou fazer-se acompanhar por este aviso. 


\section{BIBLIOALIMENTARIA}

Alimentação, Saúde e Sociabilidade à Mesa no acervo bibliográfico da Universidade de Coimbra

Carmen Soares (Coord.)
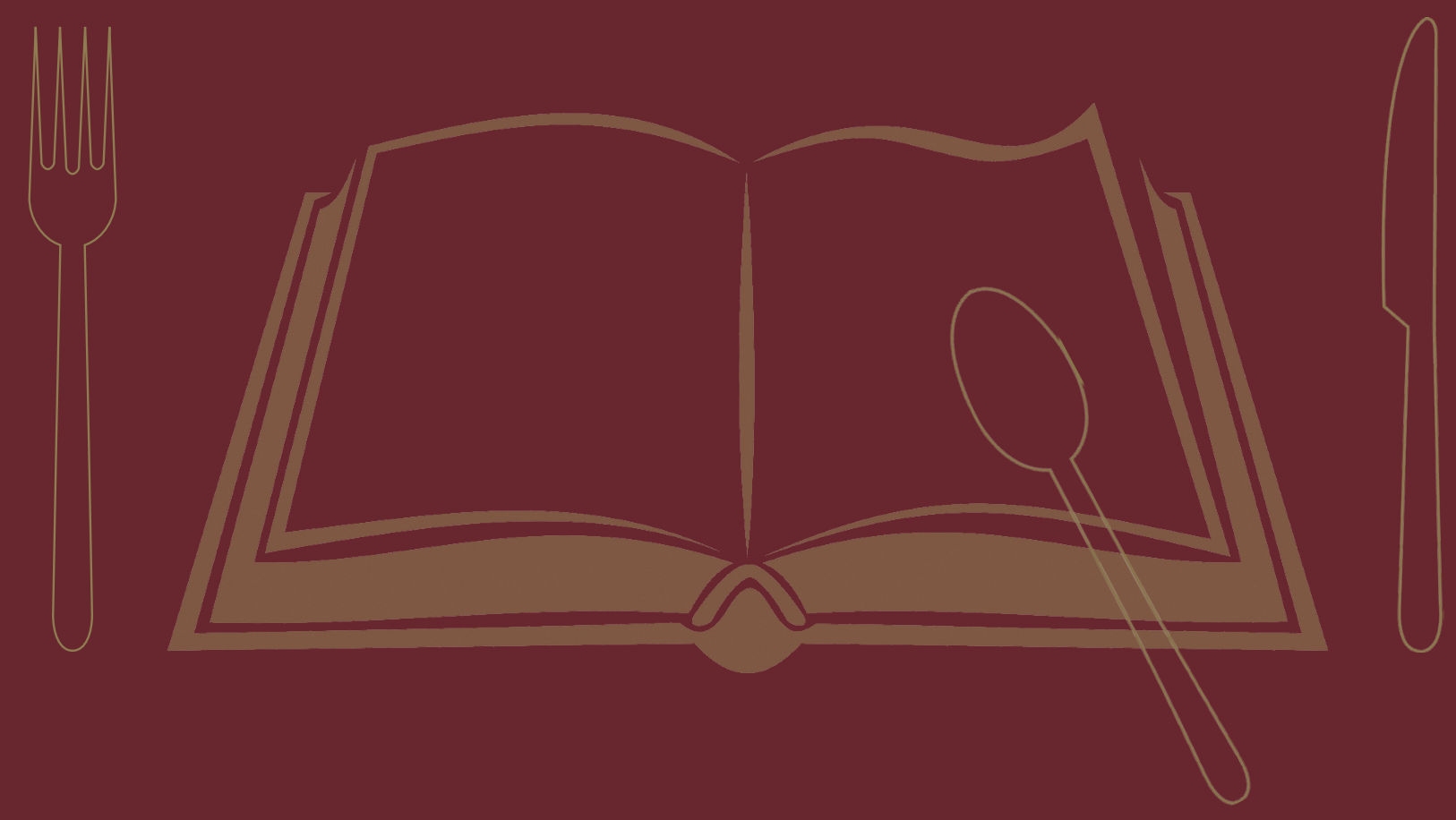

Imprensa da Universidade de Coimbra

Coimbra University Press 
Estas peças documentais foram recolhidas no espólio de um arquivo pessoal existente no AUC. Trata-se do arquivo de João Jardim de Vilhena (1873-1966), que doou à Universidade de Coimbra grande parte da sua correspondência pessoal e, sobretudo, um conjunto considerável de manuscritos, iconografia e folhetos impressos que foi reunindo ao longo da sua vida, nos quais se inclui um interessante conjunto destes cardápios, alguns deles ainda manuscritos. A designação de ementa ou de menu é utilizada indistintamente, em pequenos folhetos ou em cartões divulgativos, encontrando-se muitos deles assinados por participantes dos encontros. ${ }^{101}$ No caso da ementa de Macau, está impressa em português e também com carateres chineses e revela uma partilha de gastronomia oriental e ocidental, ao conjugar sopa de barbatana de tubarão, ninhos de salangana e ovos de pomba, juntamente com filetes de garoupa, galinha corada com presunto, etc.

Os menus ou ementas (ou ainda cardápios) foram, nos últimos anos, objeto de estudo, no Brasil, em interessantes e inovadores trabalhos de investigação, num reconhecimento da importância deste património documental para a memória gastronómica e, também sem ser apenas numa perspetiva gastronómica, podendo ser interpretados com uma leitura crítica, quanto ao seu grafismo, banquetes ou homenagens para os quais foram elaborados, locais de reunião, etc. Podem referir-se aqui as coleções de menus que foram objeto desses estudos: a que foi reunida pelo Imperador do Brasil D. Pedro II, e que foi oferecida à Biblioteca Nacional do Rio de Janeiro ${ }^{102}$, ou ainda a coleção agrupada pelo poeta e jornalista Olavo Bilac e hoje localizada na Academia Brasileira de Letras, da qual foi fundador. ${ }^{103}$

101 Refira-se o trabalho de investigação que teve por objeto o estudo de menus ou ementas: Braga, Isabel Drumond (2006), Menus em Portugal: para uma bistória das artes de servir à mesa. Lisboa: Chaves Ferreira.

102 Que serviram de tema ao trabalho de Boccato, André; Lellis, Francisco (2013), Os Banqueted do Imperador. São Paulo: Ed. Senac.

103 Parte desta coleção é divulgada no trabalho de Garcia, Lúcia (2011), Para uma bistória da belle-époque - a coleção de cardápios de Olavo Bilac. São Paulo, Imprensa Oficial.

\section{Mais de um século em prol}

\section{da agricultura: a Gazeta Jas Aldeias}

Maria Helena da Cruz Coelbo

Será uma verdade elementar afirmar que, antes de consumir, é preciso produzir. Logo, no que diz respeito à alimentação, diríamos que, antes de comer, é preciso semear, plantar, colher, se pensamos no pão, no vinho, nos legumes, nos produtos hortícolas, na fruta; criar e cuidar, se pensamos nos animais domésticos; capturar e recolher se pensamos na caça e na recoleção da cera e do mel; pescar no mar e nos rios, se pensamos no peixe; trabalhar nas marinhas, se pensamos no sal. Ao que poderíamos acrescentar todo um leque de tarefas nos moinhos, nos lagares de vinho ou azeite, na confeção e conservação dos produtos alimentares, para só nos atermos às atividades mais básicas.

Assim, porque o homem para subsistir se teve de nutrir, necessário foi que caçasse, recolhesse ou agricultasse. E, desde que aprendeu a trabalhar a terra, foi-se continuamente esforçando por colher mais e melhores frutos.

A agricultura, que surgiu no Crescente Fértil há muitos milhares de anos, em conjugação com a sedentarização das populações e a domesticação dos animais, foi porém evoluindo muito lentamente no contexto de uma longuíssima duração. Houve de facto mudanças na adaptação de diferentes sementes e plantas, nas técnicas de cultivo, nos pousios, nas rotações de culturas e preparação dos solos, nas alfaias agrícolas (mais operativas com a aplicação de peças de ferro), no aproveitamento de diversas forças motrizes, nos diferentes modos de produção, mas verdadeiramente a revolução agrícola correu a par com a revolução industrial nos séculos XVIII e XIX. A indústria modernizou a agricultura com a maquinaria agrícola, com a aplicação dos químicos, dos adubos aos pesticidas, com a melhoria dos transportes, fomentando o estímulo do mercado. 
Portugal só a partir dos finais do século XIX se está a abrir a esses novos impulsos. Não se apresentou, porém, imutável a paisagem agrícola portuguesa. Nela a tradicional cerealicultura foi-se caldeando com as culturas mediterrânicas, com preponderância da vinha, para depois dos Descobrimentos incorporar a cultura do milho maís, como séculos mais tarde a do arroz e a da batata. Os movimentos de crescimento demográfico exigiram novos arroteamentos e técnicas de cultivo, da mesma forma que uma economia natural e uma agricultura de autossubsistência se foram transmutando, com o desenvolvimento da vida urbana e de uma economia monetária, numa agricultura de mercado, permeabilizada à influência do capital e de uma produção empresarial ${ }^{104}$.

Mas é verdadeiramente apenas nos finais do século XIX e por todo o seguinte que as mutações na agricultura se tornam verdadeiramente significativas ${ }^{105}$. Na segunda metade de Oitocentos viveu-se uma época de crescimento demográfico que conduziu a transformações económicas, assistindo-se ao crescimento urbano, à industrialização e igualmente ao aumento da emigração. Todavia, ainda que se verificasse uma maior concentração nas áreas urbanas, onde se implantavam justamente as indústrias, Portugal era ainda um país mais de vilas e aldeias do que de cidades e no total dos seus habitantes, em torno de cinco milhões e meio, cerca de $65 \%$ da população ativa dedicava-se ao sector primário ${ }^{106}$. O progresso económico do país foi impulsionado pelas reformas institucionais dos diversos governos e por uma política forte de investimento público nas áreas dos transportes e das comunicações, levada a efeito por Fontes Pereira de Melo.

$\mathrm{Na}$ indústria assinalaram-se desenvolvimentos na transformação da cortiça e das conservas de peixe, indústrias ligadas à exportação,

104 Um quadro alargado, temporal e regionalmente, da evolução da agricultura em Portugal, apresenta Orlando Ribeiro (1971), "Agricultura”, in Dicionário de História de Portugal, vol. I, Porto, Livraria Figueirinhas, pp. 60-66.

105 Maria Carlos Radich (1996), Agronomia no Portugal Oitocentista: uma discreta desordem, Oeiras. Celta.

106 Teresa Rodrigues Veiga (2004), "As realidade demográficas", in Portugale a Regeneração (1851-1900), coord. de Fernando Rosas e A. H. de Oliveira Marques, vol. X de Nova História de Portugal, dir. de Joel Serrão e A. H. de Oliveira Marques, Lisboa, Editorial Presença, pp. 36-40. e nos químicos e cimentos, em conexão com o mercado interno. No sector primário sentiu-se o impacto da abolição das estruturas herdadas do Antigo Regime, desde logo com a extinção das Ordens Religiosas e a nacionalização dos seus bens. Beneficiou também este da expansão do mercado interno, exigido pelo crescimento urbano, e mais ainda do aumento da demanda dos mercados externos, em particular o britânico e o francês e muito em especial em relação ao vinho, ainda que a crise do oídio, em 1850, e da filoxera, nos inícios de 1870, o tivesse afetado. Recolheu igualmente as vantagens da construção de uma rede de estradas e de vias ferroviárias que promoveram a distribuição interna e externa dos produtos ${ }^{107}$.

Assistimos assim ao acréscimo da área cultivada, dos arroteamentos, a transformações na organização das explorações em relação com o mercado e, embora em menor escala, também a certas inovações técnicas. Ainda que o crescimento agrícola tenha sido predominantemente extensivo, não se pode negar a influência positiva que sobre ele teve a utilização de adubos químicos e a mecanização, embora estas novidades fossem introduzidas muito lenta e irregularmente. As descobertas de Justus Liebig na década de 1840, identificando os principais elementos minerais presentes no solo responsáveis pela nutrição das plantas, determinaram que o uso de adubos passasse a ser uma prática corrente. Em Portugal os adubos modernos começaram a aplicar-se a partir de 1870 nas vinhas, mas só nos finais do século o seu uso se tornou mais frequente, tanto na vinha como nos cereais. Por sua vez a mecanização foi mais difícil e apenas nos finais da centúria teve algum impacto, em particular nas propriedades de maiores dimensões, no Alentejo e no Ribatejo. Também nas técnicas de cultivo houve melhorias, como a diminuição do pousio pela rotação campo-prado, com a introdução nos terrenos de cereais de novas plantas forrageiras e com o aumento da criação de gado, favorecendo a estrumação ${ }^{108}$.

107 Octávio Figueiredo (2004), João Pedro Ferro, Rui Pedro Esteves, "As pulsões económicas e financeiras”, in Portugal e a Regeneração ..., pp. 71-74.

108 Octávio Figueiredo, João Pedro Ferro, Rui Pedro Esteves (2004), "As pulsões económicas e financeiras”, in Portugal e a Regeneração..., pp. 74-81. Na continuidade da análise das questões da agricultura, pecuária e pescas, na transição da monarquia para a república, veja-se A. H. de Oliveira Marques e Fernanda Rollo (1991), “Agricultura, pecuária e pescas”, in Portugal da Monarquia 
Segundo Pedro Lains, cerca de $80 \%$ do valor da produção total agrícola em meados do século XIX abrangia as produções de vinhos, de cereais (milho, trigo e centeio) e os produtos animais e, entre 1851 e 1900, assinalava-se no produto agrícola uma taxa de crescimento média anual acumulada de cerca de 1,0\%109.

Foi neste contexto demográfico e económico que nasceu a publicação que se apresenta.

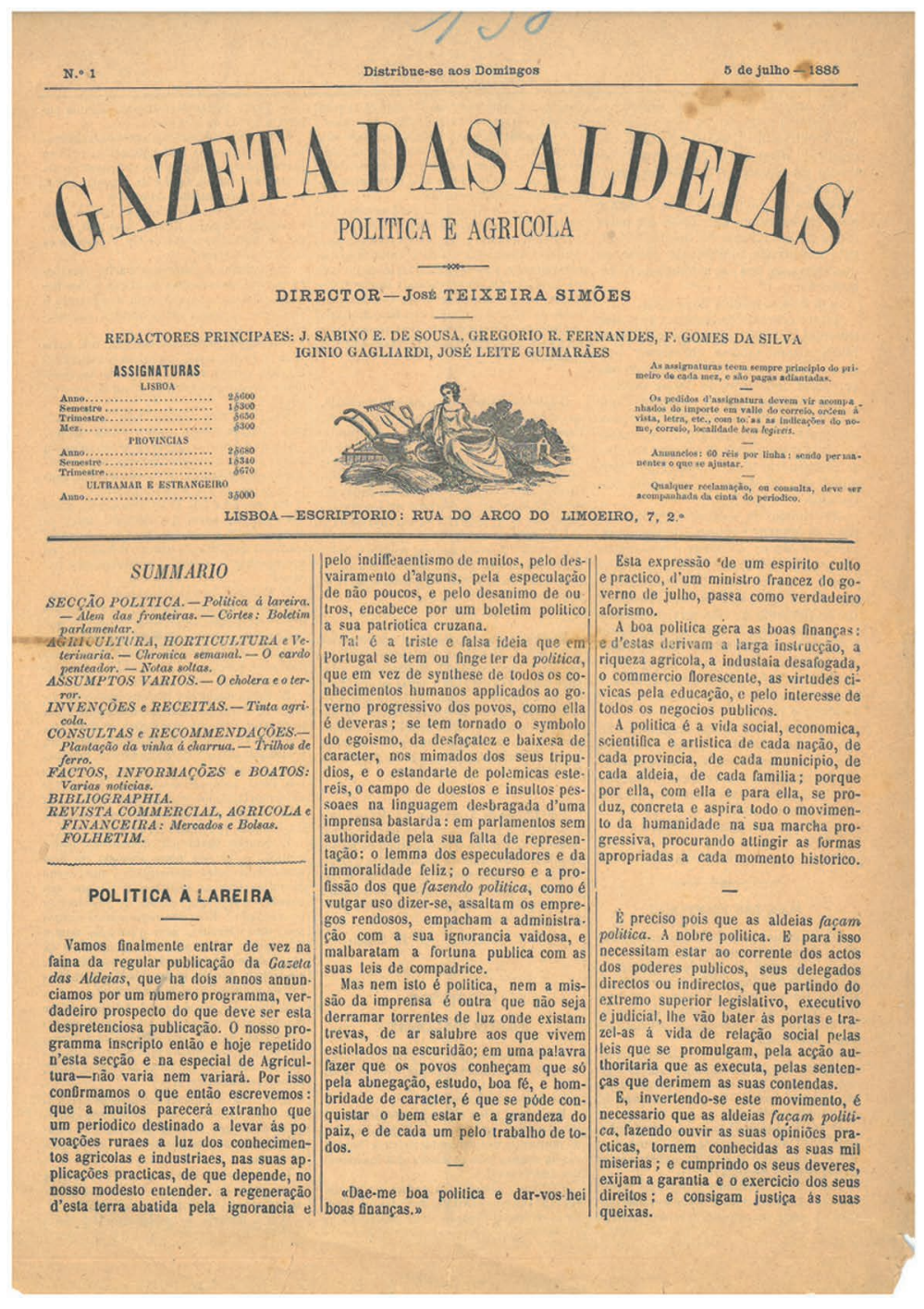

para a República, coord. de A. H. de Oliveira Marques, vol. xi de Nova História de Portugal, dir. de Joel Serrão e A. H. de Oliveira Marques, Lisboa, Editorial Presença, pp. 65-114.

109 Pedro Lains (1990), A evolução da agricultura e da indústria em Portugal, 1850-1913. Uma interpretação quantitativa, Lisboa, Banco de Portugal, pp. 9-29.
A exposição exibiu, de facto, num dos seus expositores, um número da Gazeta das Aldeias, um periódico agrícola deveras interessante, ainda que muitos outros dedicados a essa matéria tivessem sido publicados em Oitocentos. Lembremos, desde logo, que antes deste existiu um anterior, cujo número um saiu em Lisboa, a 5 de Julho de 1885, designando-se Gazeta das Aldeias. Politica e Agricola, cujo Director era José Teixeira Simões, periódico que sobreviveu apenas até $1887^{110}$.

Já a Gazeta das Aldeias, "semanario de propaganda agricola e vulgarisação e de conhecimentos uteis", que surgiu com o seu número primeiro, no Porto, no Domingo, 5 de Janeiro de 1896, teve uma longa vida. Os seus proprietários foram o Padre João Pereira Vidal e Júlio Gama e tinha como redator principal o químico analista do Laboratório Químico-Agrícola do Porto, o Dr. António Magalhães.

Nascido na agitada década de 90 da Monarquia Constitucional, em que eram candentes os problemas políticos e as questões coloniais, ainda que caíssem governos e regimes, o periódico sobreviveu até ao ano 2000, convivendo com a implantação da República, a ditadura militar imposta em 1926, o Estado Novo e o salazarismo desde 1933, a Revolução de Abril de 1974 e os tempos de Democracia a partir de então. Ao longo dessas décadas passou de semanal a quinzenal, em 1934, e depois a mensal, em 1976. Se bem que tenha mantido o mesmo nome teve, após a implantação da Democracia, primeiro o subtítulo de "Revista de Divulgação Agrícola” (1976) e depois, em 1996, reclamando o seu secular passado, anuncia-se, como "Revista Centenária do Mundo Rural"111. E durante tão duradouro trajeto esse periódico agrícola foi mesmo galardoado com diversas medalhas e distinções ${ }^{112}$.

110 Existente, por exemplo, na Biblioteca Municipal de Coimbra - Maço 34. 111 Todavia, já pelo menos em 1995, ano 99.', se designava "Revista do Mundo Rural".

112 A Gazeta das Aldeiad, nos anos 81..$^{\circ}$ e 82..$^{\circ}$, respectivamente de 1976 e 1977, refere que teve Medalhas de Ouro, Prata e Bronze em exposições nacionais e brasileiras (1897, 1898, 1901, 1904, 1908, 1929, 1950), sendo também louvada por portaria dos Ministros da Instrução e Agricultura. 


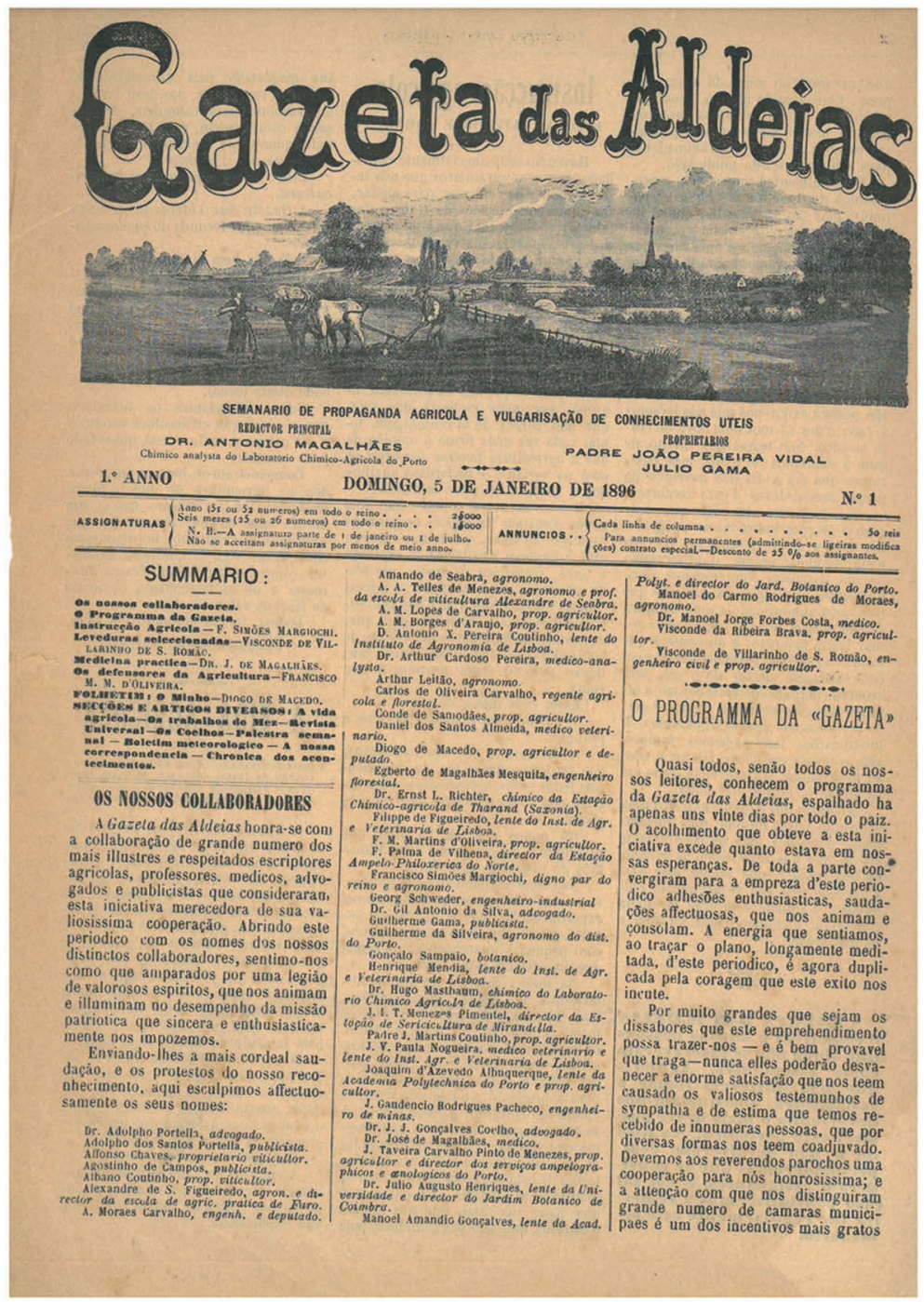

Na revista escreveram agrónomos, químicos, botânicos, regentes agrícolas e florestais, professores universitários, engenheiros, médicos, advogados, proprietários, agricultores e viticultores, diretores de diversas instituições públicas, publicistas, deputados e outros, expondo os seus conhecimentos, defendendo as suas convicções, fazendo eco nos seus artigos das diversas políticas, ideologias e conhecimentos que se propalavam para a agricultura. O primeiro número arrolava desde logo o nome de muitos desses que aderiram à publicação do semanário. Pelo que se percebe ao ler o artigo "O Programma da 'Gazeta', incluído nesse número, teria havido uma prévia divulgação dos seus objetivos, que fora bem aceite por párocos, câmaras e outras pessoas e entidades, embora o mesmo não se detalhe, deixando porém bem clara a convicção e o voto dos seus promotores: "A Gazeta das Aldeias nasceu d'uma aspiração talvez ousada, mas sinceramente patriótica, mas verdadeiramente cívica. Não nos abandonem os homens de boa vontade, que amam este paiz e anceiam pelo seu resurgimento económico..." 113 .

O exemplar mais antigo existente na Biblioteca Geral da Universidade de Coimbra, e que surge nesta exposição, corresponde ao $12^{\circ}$ ano, que se inicia com o número 576, a 13 de Janeiro de 1907 e segue até ao número 626, de 29 de Dezembro ${ }^{114}$. Logo a abrir explica-se que houve uma crise na revista, ultrapassada pelo aumento de assinaturas, aludindo-se mais genericamente à dificuldade de existência de revistas de agricultura.

O temário principal da revista é vastíssimo, abrangendo artigos sobre agricultura (continental, colonial e até comparada com a de outros países), silvicultura, fruticultura, viticultura, tecnologia rural, apicultura, avicultura e carnes, entre outros. Mas certas rubricas revestem-se de uma função eminentemente didática, como por exemplo o espaço "A Nossa Correspondência”, em que sob a forma de pergunta-resposta se colocam as mais variadas questões, que são esclarecidas com precisão pelo semanário. Já sob o título "Higiene e Medicina" se apresentam úteis recomendações práticas de saúde. Por sua vez, o item "Economia Doméstica” trata de alimentos, sua forma de conservação e confeção, incluindo muitas receitas culinárias, e diversos outros aspetos relacionados com a cozinha e a alimentação. Não deixa mesmo a revista de anunciar espetáculos e incluir folhetins para atrair os leitores e as leitoras,

113 Número existente, por exemplo, na Biblioteca Municipal de Coimbra Maço 34.

114 A Biblioteca Geral da Universidade de Coimbra possui a revista desde o ano 12, n. 576, de 13 de Janeiro de 1907, ao ano 30, n. 1371, de 27 de Dezembro de 1925, com a cota A-16-48-2; e do ano 31, n. 1372, de 3 de Janeiro de 1926, ao ano 104 n. 3084 de Janeiro/Março de 2000, com a cota A-16-49/52. Na coleção faltam, porém, os seguintes números: 939, 1170, 1249, 1259, 1264, 1270, 1302, 1340, 1345, 1348, 1467, 1496, 1776, 1792, 1878, 2729, 2929, 3037 a 3043, 3047, 3049, 3050, 3053, 3067 a 3083. Estas informações foram gentilmente cedidas pelos Drs. Maria Luísa Machado e José Mateus, a quem agradecemos todas as amabilidades que nos dispensaram para a elaboração deste trabalho. 
da mesma forma que se abre a múltiplos anúncios, ligados, por via de regra, à agricultura. Aumentando a operacionalidade do seu manuseio, em junho e dezembro o semanário incorpora um índice alfabético e metódico, respetivamente do primeiro e segundo semestres desse décimo segundo ano ${ }^{115}$.

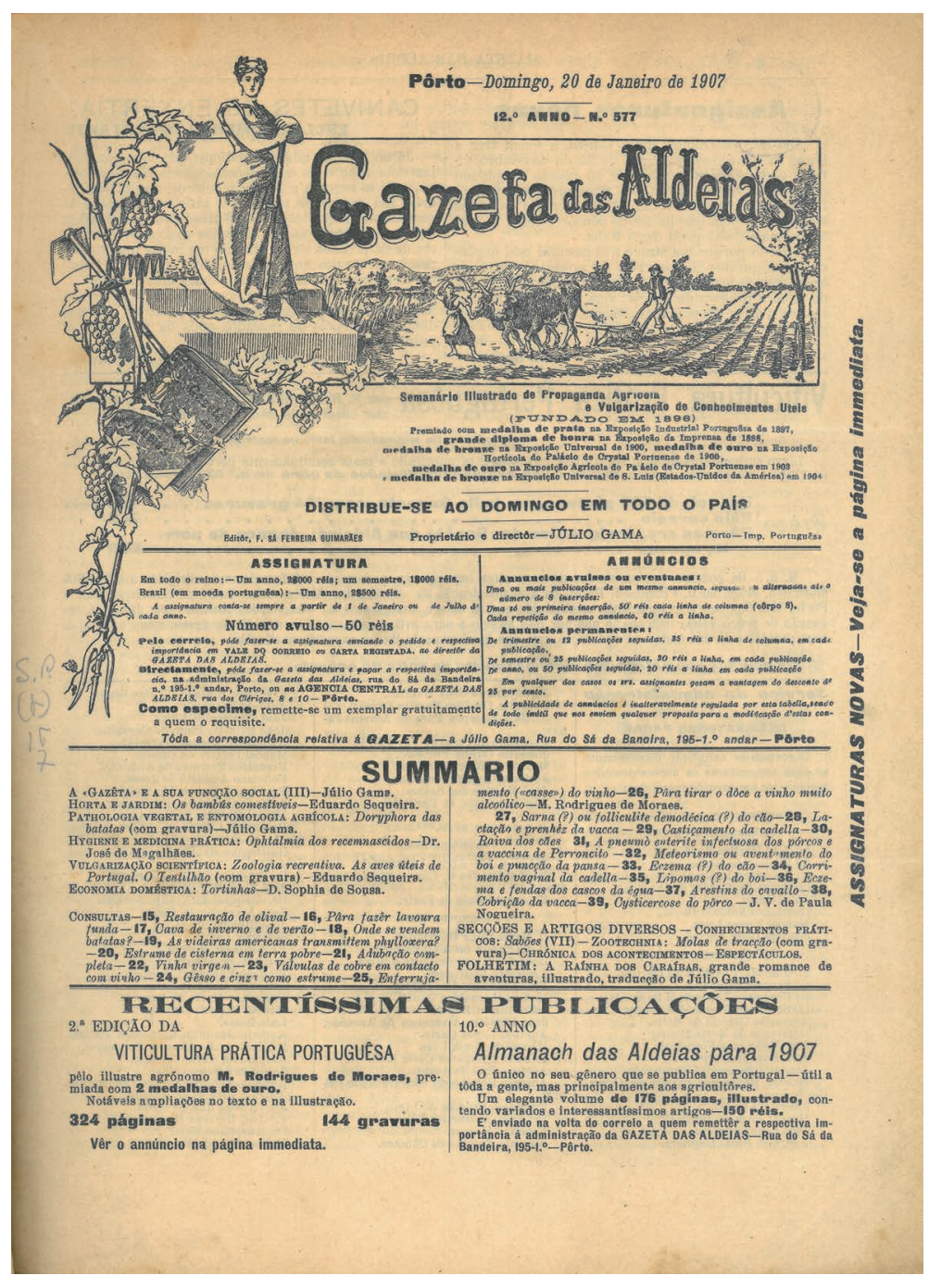

$\mathrm{Na}$ política de protecionismo e dirigismo do Estado Novo, que tinha em vista o aumento da produção e a autossubsistência alimentar, a revista e os seus colaboradores acompanharam a

115 Consultámos o periódico, por amostragem: os anos de 1907, 1929, 1930 , 1938, 1939, 1942, 1976, 1977, 1992 e alguns números de 1995, 1996, 1997, 1998 e 2000 .
Campanha do Trigo de 1929, a campanha da fruta na segunda metade dos anos 30, os planos de obras hidráulicas e os planos de povoamento florestal, medidas com diferentes impactos na paisagem agrária, na economia e na estruturação social ${ }^{116}$.

Algumas etapas importantes foram sendo concretizadas com as obras hidráulicas, permitindo uma maior área irrigada e aumentando consideravelmente a produção de arroz, com a generalização do emprego dos adubos químicos (que foram fundamentais nas pragas das vinhas), com a introdução da maquinaria agrícola, com a supressão do pousio (alterando a cultura do cereal com a das leguminosas), com a valorização do trigo face aos demais cereais, ainda que todos estes passos tivessem sido bastante lentos e muito influenciados pelas ideologias políticas e sociais. De facto, como afirma Fernando Rosas, a prolongada situação de atraso e estagnação da agricultura até ao final do regime deve-se à contradição entre "um reformismo agrário com influência suficiente para ser Governo e definir políticas, mas sem poder real para as executar; do outro, um ruralismo conservador aparentemente já sem força para ser poder, mas ainda com capacidade política e ideológica para se opor ao seu exercício" ${ }^{117}$.

A Gazeta das Aldeiad, logo em 1930, faz de facto eco da Campanha do Trigo, mas muito criticamente discute os seus perigos e mesmo o alcance dos seus resultados ${ }^{118}$, o que foi até contestado pelos órgãos públicos oficiais, embora também publique as normativas governativas para a prossecução da mesma. Aborda ainda outros temas, como a agricultura e a indústria, a cultura da batata, a caixa e os sindicatos ou a segunda exposição do milho ${ }^{119}$. Por sua vez, nos inícios da década de 40, a revista, que é já quinzenal e apresenta um formato de menores dimensões em altura e

116 Leia-se Luciano do Amaral (1994), “Agricultura e política agrícola. O país que nós perdemos”, in Fernando Rosas, O Estado Novo (1926-1974), vol. 7 de História de Portugal, dir. de José Mattoso, Lisboa, Editorial Estampa, pp. 431-440.

117 Fernando Rosas (1991), "Rafael Duque e a política agrária do Estado Novo (1934-44)”, Análise Social, XXVI (112-113), (3. 4. ${ }^{\circ}$ ), p. 790 (todo pp. 771-790).

118 Gazeta das Aldeias, 35. ${ }^{\circ}$ ano (1930), ns. 1582, 1583-92, 1956, 1600, entre outros.

119 Gazeta das Aldeias, 35. ${ }^{\circ}$ ano, n. 1631. 
largura ${ }^{120}$, muito mais manuseável, também se abre às novidades e cientificidade da política agrícola de Rafael Duque, contando com artigos vários sobre a Campanha da Produção Agrícola, grémios da lavoura e a sua federação e união, melhoramento de sementes, fertilizantes, repovoamento dos montados, agricultura e comércio externo e, para além de rubricas sobre as tradicionais culturas oliveira, vinha, favas, milho, batata -, insiste agora na cultura da soja. Apresenta igualmente uma secção designada "Informação. Estatística. Legislação" e outra intitulada "Previdência e economia nos meios rurais, tratando, por exemplo, dos seguros"121.

Entretanto, nos anos 50, começa a ser publicado pelo engenheiro agrónomo Artur Castilho o Manual Enciclopédico do Agricultor Português (cat. nº 85), com o patrocínio da Gazetas das Aldeias ${ }^{122}$. $\mathrm{O}$ volume que consta do presente catálogo diz respeito aos cereais e trata exaustivamente das suas espécies ${ }^{123}$, segundo um questionário vastíssimo ${ }^{124}$, que, ainda nos nossos dias, terá utilidade em ser consultado. Existem outros do mesmo autor sobre os Tubérculos Alimentares e Industriais ${ }^{125}$ e sobre as Fruteiras Alimentares ${ }^{126}$ e os Legumes Alimentared ${ }^{127}$, bem como dois da autoria do engenheiro

120 No ano de 1934, em que passa a quinzenal, reduz também a sua altura de $30,5 \mathrm{~cm}$ para $26 \mathrm{~cm}$.

121 Gazeta das Aldeias, $47^{\circ}$ ano, n. 1982 a n. 2005.

122 Manual Enciclopédico do Agricultor Português, por Artur Castilho, Agricultura, II Parte, Grupo I, Cereaid, Porto, Edição da Gazeta das Aldeias, [1954?].

123 Refere-se ao adlai, alpista, arroz, aveia, centeio, cevada, codrã, espelta, fundo, luco, massango, milhã, milhão, milho, painço, pé-de-galinha, sarraceno, sorgo, trigo.

124 Se bem que o inquérito possa variar um pouco consoante as espécies, tomando o do trigo como exemplo, verificamos que se tratam estes itens: nomes; filiação; descrição; variedades; meio; combinação; adubação; correção; lavoira; granjeios; métodos de cultura; colheita; produção; danos; usos; importância.

125 Manual Enciclopédico do Agricultor Português, por Artur Castilho, Agricultura, II Parte, Grupo III, Tubérculos Alimentares e Industriaid, fasc. 1, Porto, Edição da Gazeta das Aldeias, [s. d.].

126 Manual Enciclopédico do Agricultor Português, por Artur Castilho, II- Fruticultura especial, Grupo I, Fruteiras Alimentares, fascs. 39-40-41-42, agosto e setembro de 1952, Porto, Edição da Gazeta das Aldeias, 1952; Manual Enciclopédico do Agricultor Português, por Artur Castilho, II - Fruticultura especial, Grupo I, Fruteiras Alimentared, fascs. 73-74-75-76, Porto, Edição da Gazeta das Aldeias, 1954.

127 Manual Enciclopédico do Agricultor Português, por Artur Castilho, Agricultura, II Parte, Grupo II, Legumes Alimentared, fascs. 1-2, Porto, Edição da Gazeta das Aldeias, s.d.. agrónomo J. Duarte Amaral, sobre Os Citrinos ${ }^{128}$ e As Pomoideas ${ }^{129}$ (macieira e pereira).

Depois da revolução de Abril os periodistas convivem e fazem eco da reforma agrária, com a ocupação das terras dos proprietários absentistas e depois das suas expropriações e a criação de cooperativas de produção agrícola até aos efeitos da entrada de Portugal na CEE, em $1986^{130}$, e o impacto da Política Agrícola Comum da União Europeia ${ }^{131}$, que genericamente condiciona os destinos da agricultura portuguesa e da sua produção alimentar até aos dias de hoje.

Numa consulta dos anos 81 e 82 da revista, já então mensal, respeitantes a 1976 e $1977^{132}$, deparamos com artigos referentes à reforma agrária, ao relatório do Comité da Agricultura da O.C.D.E., ao plano do Alqueva, à adesão ao Mercado Comum, à explanação de “O que é a C.E.E.”, à produtividade das empresas agrícolas, entre muitos outros, demonstrando as novas preocupações agrárias depois da revolução e o alargamento do mercado a espaços muito mais amplos e sujeitos a diversas políticas europeístas e mundiais. Curiosamente, em 1976, a revista lança um inquérito designado "Como acha a nossa Revista”, devendo os leitores pronunciar-se sobre a sua apresentação e os assuntos nela tratados, numa salutar preocupação com a melhoria da sua qualidade e com o intuito de ir ao encontro dos interesses dos seus leitores. Já depois da adesão de Portugal à CEE, por exemplo em 1992, o periódico contém artigos sobre o FMI, a reforma da

128 Manual Enciclopédico do Agricultor Português, III Parte, II, Fruticultura especial. Grupo I. Fruteiras alimentares (3. ${ }^{\circ}$ volume), Os Citrinos, fascs. 1-2, janeiro de 1957, Porto, Edição da Gazeta das Aldeias, 1957.

129 Manual Enciclopédico do Agricultor Português, III Parte, II, Fruticultura especial. Grupo I. Fruteiras alimentares ( $4^{\circ}$ volume), As Pomoideas, fascs. 1-2, outubro de 1958, Porto, Edição da Gazeta das Aldeias, 1958.

130 Consulte-se a síntese da reforma agrária na geografia da revolução de Abril de José Medeiros Ferreira (1994), Portugal em trande (1974-1985), vol. 8 de História de Portugal, dir. de José Mattoso, Lisboa, Editorial Estampa, pp. 121-137. 131 Uma análise crítica desta política encontra-se na obra de Boaventura de Sousa Santos (1994), Pela mão de Alice: o social e político na pós-modernidade, Porto, Edições Afrontamento.

132 Gazeta das Aldeias, ano 81. (1976), ns. 2798-2809; ano 82. (1977), n. 2810-2821. 
PAC, a agricultura portuguesa e a CEE, a sociologia agrária ou a agricultura na TV, mostrando-se em contínua atualização ${ }^{133}$.

O último número que a Biblioteca Geral da Universidade de Coimbra possui da Gazeta das Aldeias diz respeito ao ano de $2000^{134}$ e nele surgem notícias sobre a Ovibeja, o termo da época de caça em fevereiro, a seca desse ano, o programa de ajudas à agricultura familiar, as leis das abelhas, o crescimento do mercado português de agroquímicos, a qualidade do azeite, a PAC, um colóquio-demonstração na Universidade de Évora, entre outras, e artigos mais informativos sobre as zonas vulneráveis e as boas práticas agrícolas, uma experiência vivida no Alentejo (herbicidas), a cultura do tomateiro, as bananas e as bananeiras, a bolbicultura no século XXI e ainda o problema das moscas em explorações de vacas leiteiras.

Um periódico como a Gazeta das Aldeias, que dura mais de um século, é um monumento, é uma memória escrita perene do passado de um país, a desafiar os historiadores ao seu estudo profundo, iluminando as múltiplas vertentes da agricultura e da produção alimentar, as quais em si mesmas são reflexo e se projetam na política, na economia, na sociedade e nas ideologias de uma Nação e de um Estado.

\section{A lei da mesa. As praxes da etiqueta e as boas maneiras} na sociedade de bom-tom: algumas fontes para o seu estudo (sécullo XIX-princípios do sécullo $\mathbf{x x}$ )

Irene Vaquinbas
133 Gazeta das Aldeias, ano 97 (1992), ns. 2990-3001.

134 Gazeta das Aldeias. Revista Centenária do Mundo Rural, ano 104, n. 3084, janeiro, fevereiro, março 2000.
Os preceitos enunciados foram retirados de manuais de civilidade editados em Portugal, no último quartel do século Xıx e inícios do século xx, correspondendo a traduções de manuais franceses ou a cópias atualizadas de anteriores edições portuguesas. Género literário de cunho pedagógico e moral, este tipo de manual tinha como principais destinatários jovens em idade escolar que frequentavam estabelecimentos de ensino. É o caso, entre outros que se poderiam referir, do Real Colégio Ursulino das Chagas de Cristo, de Coimbra, reservado a meninas das elites, cuja aprendizagem, em termos de civilidade, se norteava pelos ensinamentos prestados por Monsenhor Prevost nos seus Elementos de Civilidade e da decencia que se practica entre gente de bem (cat. n. ${ }^{\circ}$ 93), obra publicada em 1788, na qual reservava um capítulo ao "que 